\title{
A myna problem: alien species no obstacle to recovery for the Mangaia kingfisher
}

\author{
Tom Thacker, Philip J. Seddon, Yolanda van Heezik and Gerald McCormack
}

\begin{abstract}
Endemic island species are of conservation interest as unique taxa, often with restricted populations, but many are data poor. The Mangaia kingfisher Todiramphus ruficollaris, known locally as the tanga'eo, is endemic to the island of Mangaia in the Cook Islands, and categorized as Vulnerable on the IUCN Red List. The population size has not been estimated since 1996, despite concerns over habitat loss and competition with an invasive species, the common myna Acridotheres tristis. We provide new population estimates for both the tanga'eo and the common myna, using the same methodology as previous estimates. During December 2018-February 2019 we surveyed with distance sampling along 73 line transects walked across the six habitat types on Mangaia. We estimate there are 4,106 tanga'eo on Mangaia (95\% CI 3,191-5,283), a dramatic 7-8 fold increase compared to the previous estimate of $393-764$. We estimate there are 13,350 common myna (95\% CI 10,998-16,206), a slight increase, although densities in the two most favoured habitats for myna have declined. There is no evidence that the common myna poses a threat to the viability of the tanga'eo population, as the latter has increased despite a much larger population of common myna. Presumed declines in the tanga'eo population in the past were probably a result of habitat loss as a result of the cultivation of pineapples Ananas comosus for export, an industry that collapsed in the 1980 os. We recommend a review of the IUCN Red List status of the tanga'eo.
\end{abstract}

Keywords Acridotheres tristis, common myna, Cook Islands, distance sampling, Mangaia kingfisher, population size, tanga'eo, Todiramphus ruficollaris

Supplementary material for this article is available at doi.org/10.1017/So030605320000071

\section{Introduction}

$\mathrm{n}$ the face of unprecedented losses in global biodiversity, 1 conservation efforts have increasingly targeted endemic species in biodiversity hotspots (Brooks et al., 2002). The

TOM THACKER (Corresponding author, (1) orcid.org/0000-0003-1308-0639),

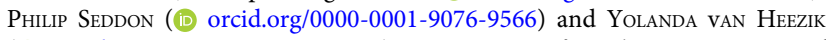
(ㄷ) orcid.org/0000-0003-0494-5311) Department of Zoology, University of Otago, 340 Great King St, North Dunedin, Dunedin 9016, New Zealand E-mail tom@thacker.info

Gerald McCormack Cook Islands Natural Heritage Trust, Rarotonga, Cook Islands

Received 2 August 2019. Revision requested 30 October 2019.

Accepted 3 February 2020. First published online 19 November 2020. islands of Polynesia and Micronesia comprise one such hotspot (Myers et al., 2000). However, for many species, a lack of available data has impeded attempts to devise conservation management plans (Bland et al., 2015). The Mangaia kingfisher Todiramphus ruficollaris, known locally as the tanga'eo, is endemic to the island of Mangaia in the Cook Islands in the tropical South Pacific, and is categorized as Vulnerable on the IUCN Red List (BirdLife International, 2016).

Although the tanga'eo has previously been described as a distinct species (Pratt et al., 1987; Sibley \& Monroe, 1990), it has also been listed as a subspecies of Todiramphus tuta (Fry et al., 1992; Rowe \& Empson, 1996a), the only other member of this genus found within the Cook Islands, on the islands of Atiu and Mauke. However, phylogenetic analyses of the genus Todiramphus support the distinction of the tanga'eo as a separate species (Andersen et al., 2015, 2018).

As a forest-dwelling species, the loss of available habitat is a significant threat (Rowe \& Empson, 1996a): the past intensive cultivation of pineapples Ananas comosus, in particular, led to the removal of tracts of forest on Mangaia. Furthermore, the introduction of the common myna Acridotheres tristis may have contributed to the decline of the tanga'eo (Rowe \& Empson, 1996a). The common myna was first introduced to Mangaia in the early 2oth century but did not become abundant until an introduction from Rarotonga in 1964 as a biocontrol agent for a coconut stick insect (Graeffea crouanii; Parkes, 2006). Common myna have been observed harassing adult tanga'eo and have been responsible for the failure of some tanga'eo nests (McCormack et al., 2008). Pineapple plantations are no longer present to the same extent following the collapse of the export industry in the 1980s (Fleming \& Blowes, 2003), but Mangaia does continue to support a large population of common myna (Baker et al., 1996). Rats Rattus rattus and Rattus exulans are present on Mangaia, but are not thought to affect the tanga'eo population seriously (Baker et al., 1996).

There are few published studies of the tanga'eo, although anecdotal evidence suggests the species might have declined in abundance following the introduction of the common myna (T. George, pers. comm., 2018). The most recent estimates of population size were made $>20$ years ago. Rowe $\&$ Empson (1996a) estimated a total tanga'eo population of 250-450 individuals, and Baker et al. (1996) estimated 393764 individuals using distance sampling. Distance sampling has been used effectively to estimate the abundance of other bird species (Garcia-Del-Rey, 2009), and is considered superior 
to techniques using count data to derive indices of abundance (Rosenstock et al., 2012).

Current baseline data on the population size of the tanga'eo are needed before any conservation action can be considered. Here we estimate the tanga'eo population using distance sampling and, given the concerns around potential negative interactions between the common myna and the tanga'eo, we also estimate the size of the common myna population on Mangaia.

\section{Study area}

Mangaia is the southernmost island in the Cook Islands (Fig. 1) and is the second largest by land area (5,140 ha). The wet season is November-May, and both mean rainfall and temperature are typically greater during these months (monthly means of $194.4 \mathrm{~mm}$ and $24.9^{\circ} \mathrm{C}$ ) than during the rest of the year (114.2 $\mathrm{mm}$ and $21.7^{\circ} \mathrm{C}$; IUCN, 2014).

The central region of the island is dominated by the weathered remnant of an extinct shield volcano (Merlin, 1991). Swamplands lie in the lowland area at the foot of these volcanic hills, just above sea level. Both the volcanic interior of the island and the surrounding lowlands are completely surrounded by a rampart of ancient and eroded coral limestone (known as the makatea) that extends to nearly $70 \mathrm{~m}$ altitude. The height of the makatea decreases towards the shoreline such that the terrace along the coast is at c. $15 \mathrm{~m}$ altitude.

The land area of Mangaia has six habitat types, based on geophysical areas (Merlin, 1991). Coastal Barringtonia asiatica forests occur along the lower makatea terrace, except in the south-east where this forest gives way to coastal scrubland, characterized by large stands of pandanus Pandanus tectorius trees. Primary forest can be found along the upper terrace of the makatea, comprising a number of indigenous species such as Elaeocarpus tonganus and the lantern tree Hernandia moerenhoutiana, and introduced species such as candlenut Aleurites moluccana. Secondary forest, characterized by albizia trees Falcataria moluccana, occurs in the low-lying regions around the base of the volcanic hills and around the swamps, where taro Colocasia esculenta is grown. Plantation forests of Caribbean pine Pinus caribaea and Acacia species cover the central volcanic hills. There are three villages on Mangaia, and these constitute the sixth habitat type. Coconut palms Cocos nucifera grow across the island, but are uncommon on the volcanic hills.

\section{Methods}

Distance sampling uses data, describing the distances of individuals detected during sampling, to model a detection function that can estimate the number of individuals not detected within the sampling area and thus produce a total population estimate. We walked line transects during

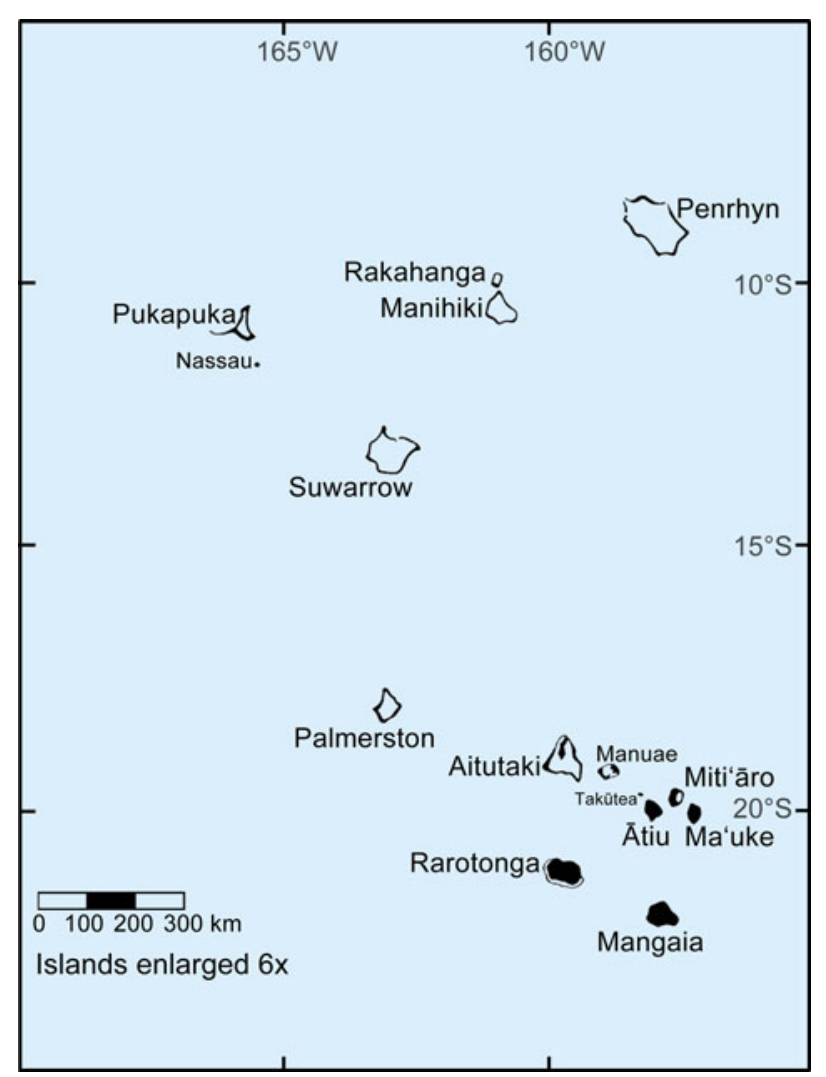

FIG. 1 Mangaia is the southernmost island in the Cook Islands, c. $200 \mathrm{~km}$ south-east of Rarotonga. The land area of each island is shaded black, including the reef flat.

daylight hours during December 2018-February 2019, attempting to survey each of the six habitat types equally. This was achieved across four of the six habitats (primary, secondary and plantation forest, and village habitats); Barringtonia forests were sampled more extensively, and coastal scrubland was sampled the least. We walked fewer transects in the latter habitat because of the limited number of detections of either species there.

Transects were established along a randomly set compass bearing, from random start coordinates. We recorded start and end coordinates using a GPS; transect length and start and end times were also recorded. The distance from the observer to each detection was recorded using a rangefinder, and the angle from the transect line determined by a compass, facilitating calculation of the perpendicular distance from the transect line to each detection (Supplementary Material 1). Detections were by either sight or sound. In instances where detections were by sound, we recorded the distances of objects determined to be closest to the source of the call. Although transect start points and bearings were chosen randomly, in some cases the topography, particularly on the makatea, dictated what was practical, and transects had to be adjusted or shortened.

Distance 6.o was used to analyse the line transect data (Buckland et al., 2015), and Akaike's information criterion 
(AIC) was then used to determine the fit of the detection functions to the data. For both species, the AIC of a detection function modelled using data pooled across habitat types was greater than the sum of the AIC values produced when modelling the detection function separately using data from each habitat type. Consequently, data were stratified by habitat type with the detection function fitted separately for each habitat. No truncation or grouping of the data was used. Analyses were run using the Conventional Distance Sampling engine, and the models with the lowest AIC score and the smallest pooled coefficient of variation were selected. A half-normal key function and a cosine series expansion were chosen as the simplest best fit for the tanga'eo data; for the common myna, a hazard-rate key function with a simple polynomial series expansion was selected.

Spatial analysis of the data was carried out in ArcMap 10.6.1 (Esri, Redlands, USA). Examination of satellite imagery of Mangaia combined with ground truthing allowed the total areas of each habitat type to be calculated. These areal estimates were subsequently used in the Distance analysis to derive abundance estimates from estimated habitat-specific densities.

\section{Results}

Across 73 transects totalling $38.17 \mathrm{~km}$ (Fig. 2), 189 tanga'eo and 986 common myna were detected. Tanga'eo were not detected in the coastal scrubland, but were otherwise recorded in each of the other five habitats; common myna were detected in all six habitat types.

The total tanga'eo population was estimated to be 4,106 individuals ( $95 \%$ CI 3,191-5,283; Table 1). The highest densities of tanga' $e o$ were recorded in the secondary and primary forest habitats (Fig. 3); few were found in and around the villages. The coastal Barringtonia forests had high densities of tanga'eo but contributed relatively few tanga'eo to the overall estimate because of the small extent of this habitat. The area covered by the plantation forest meant this habitat harboured a larger number of tanga'eo despite the lower density than in the Barringtonia forests. The pooled coefficient of variation $(\mathrm{CV})$ for all of the habitats was $12.7 \%$; for each of the individual habitats the $\mathrm{CV}$ was higher. Secondary forest had the smallest CV (16.1\%), whereas Barringtonia forest had the largest (39.9\%).

The common myna was estimated to have a population size of 13,350 individuals ( $95 \%$ CI 10,998-16,206; Table 1). The highest densities were in and around the villages and in the secondary forest, where the majority of individuals were found (Fig. 3). The coastal habitats supported fewer individuals than the inland habitat types, and the habitat with the lowest density of common myna was the plantation forest. The pooled CV for all habitat types was 9.8\%; secondary forest had the smallest CV (11.7\%) and coastal

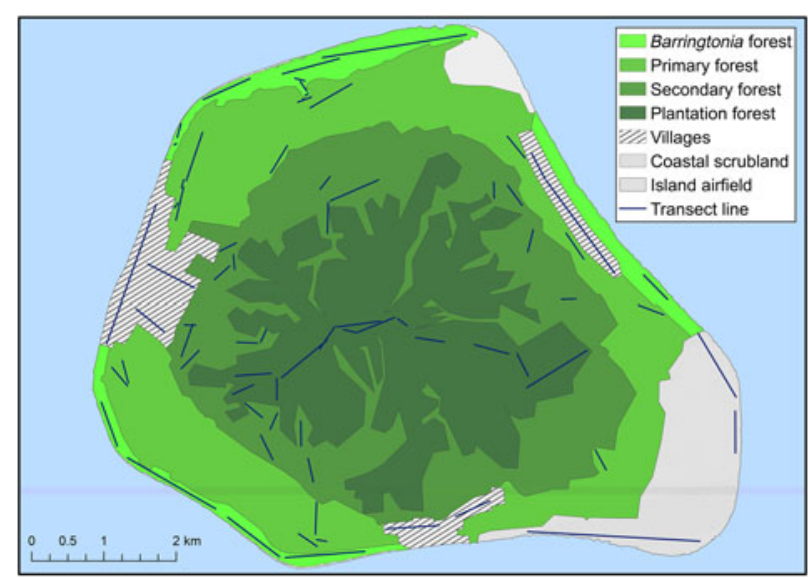

Fig. 2 Locations of the 73 transects surveyed across Mangaia during December 2018-February 2019. The area in the northeast of the island without any transects is where the airstrip is located; this was not considered a separate habitat type and was ignored for sampling purposes.

scrubland and plantation forest had the highest (80.1 and $50.3 \%$, respectively).

\section{Discussion}

This is only the second population estimate for the tanga'eo on Mangaia using distance sampling, and it indicates that the population has increased since 1996. Our findings suggest that the common myna population has also increased during this time. Both species occur at high densities within the secondary forest habitat on Mangaia.

We surveyed a greater number of habitats than Baker et al. (1996), although our results suggest that the density of tanga'eo has increased in each of the three habitats (primary, secondary and Barringtonia forests) surveyed in 1996. The areal extents of primary and Barringtonia forest $(1,309$ and 301 ha, respectively, in 2019) do not appear to have changed substantially since 1996 (1,118 and 194 ha). Secondary forest appears to have increased $(1,270$ ha compared to 397 ha; Baker et al., 1996). This disparity appears to be a result of Baker et al.'s (1996) decision to distinguish agricultural land occurring in the lowlands surrounding the central volcanic hills from secondary forest. In contrast, our study considered secondary forest and agricultural land as a single, continuous habitat type, based on our observations that the tanga'eo and common myna occurred at similar frequencies in these two areas. Consequently, although our results suggest that the tanga'eo population has increased from 218 (Baker et al., 1996) to 2,102 in the secondary forest, the initial estimate from 1996 might have underestimated the number of tanga'eo in this habitat. Another factor potentially contributing to an underestimate in 1996 was that neither the central plantation forest nor the village habitats were surveyed (Baker et al., 1996). Rowe \& Empson (1996a) 
TABLE 1 Density and abundance of the tanga'eo Todiramphus ruficollaris and the common myna Acridotheres tristis across the six habitat types on Mangaia.

\begin{tabular}{|c|c|c|c|c|c|c|c|}
\hline & \multirow{2}{*}{$\begin{array}{l}\text { Area } \\
\text { (ha) }\end{array}$} & \multirow{2}{*}{$\begin{array}{l}\text { Total survey } \\
\text { effort }(\mathrm{km})\end{array}$} & \multirow{2}{*}{$\begin{array}{l}\text { No. of } \\
\text { transects }\end{array}$} & \multicolumn{2}{|c|}{ Density per ha $(95 \% \mathrm{CI})$} & \multicolumn{2}{|l|}{ Abundance $(95 \% \mathrm{CI})$} \\
\hline & & & & Tanga'eo & Common myna & Tanga'eo & Common myna \\
\hline Barringtonia forest & 301 & 8.67 & 13 & $0.70(0.31-1.58)$ & $1.03(0.50-2.09)$ & $209(92-474)$ & $339(166-691)$ \\
\hline Primary forest & 1,309 & 6.56 & 17 & $0.72(0.35-1.48)$ & $1.49(0.77-2.87)$ & $941(458-1,934)$ & $1,946(1,008-3,759)$ \\
\hline Secondary forest & 1,270 & 6.32 & 20 & $1.65(1.19-2.30)$ & $5.96(4.71-7.55)$ & $2,102(1,513-2,918)$ & $7,570(5,976-9,589)$ \\
\hline Plantation forest & 1,231 & 5.91 & 13 & $0.67(0.42-1.06)$ & $0.73(0.27-1.95)$ & $821(514-1,309)$ & $901(338-2,397)$ \\
\hline Village & 282 & 6.57 & 7 & $0.12(0.06-0.23)$ & $8.14(4.91-13.48)$ & $33(17-66)$ & $2,290(1,382-3,795)$ \\
\hline Coastal scrubland & 372 & 4.14 & 3 & & $0.82(0.12-5.40)$ & & $304(46-2,006)$ \\
\hline Total & 4,765 & 38.17 & 73 & & & $4,106(3,191-5,283)$ & $13,350(10,998-16,206)$ \\
\hline
\end{tabular}
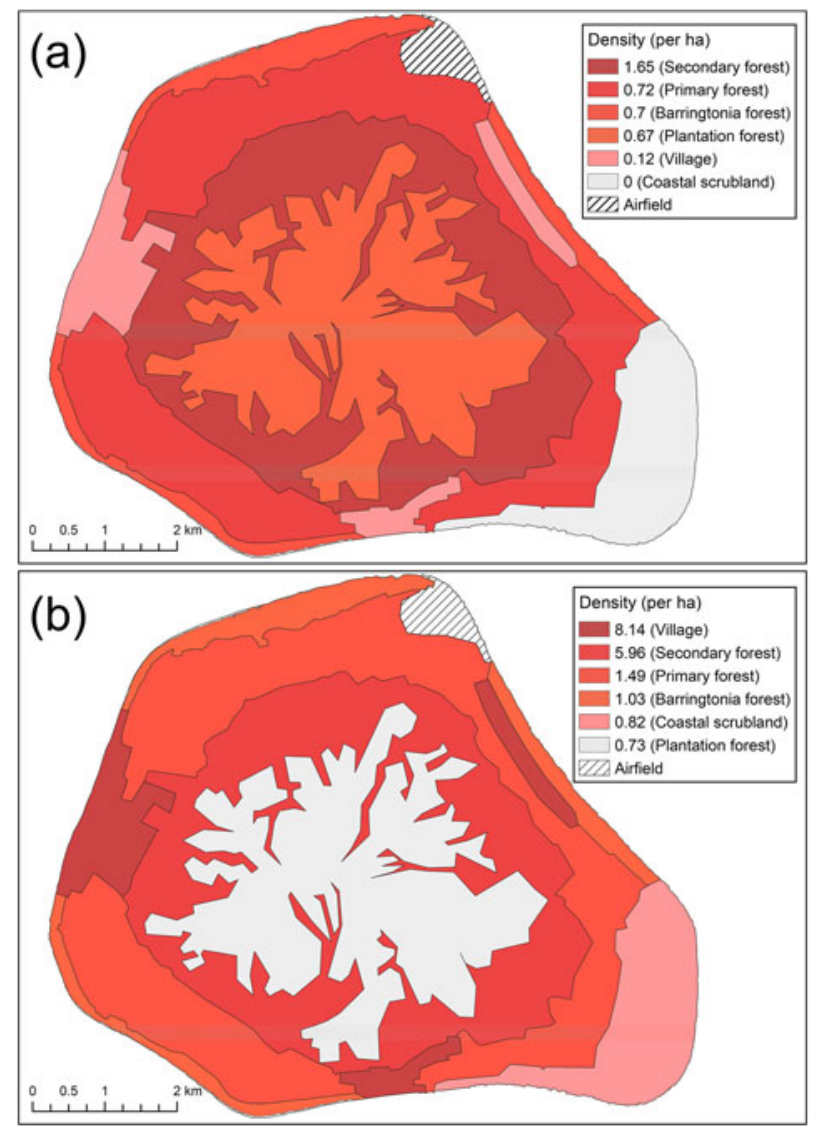

FIG. 3 Density heat maps for (a) the tanga'eo and (b) the common myna across Mangaia.

did not report that these two habitats contained large numbers of tanga'eo at that time, suggesting that the population size estimated by Baker et al. (1996) was unlikely to have been significantly affected by this omission.

To give context to our findings, the density of tanga'eo on Mangaia is similar to those of other Pacific Todiramphus species, although caution is needed when comparing estimates derived from different methodologies and at different scales. As the majority of densities reported previously for Pacific Todiramphus species are for entire islands and not individual habitats, it is helpful to consider that the average density of tanga'eo weighted for the different sizes of the habitats on Mangaia is 0.86 individuals per ha. This is greater than the density reported for the Pohnpei kingfisher Todiramphus reichenbachii ( 0.5 per ha) and for the Tuamotu kingfisher Todiramphus gambieri (o.2 per ha), but less than that of the Society kingfisher Todiramphus veneratus on the island of Mo'orea in French Polynesia (2.4 per ha; Kesler et al., 2010).

For the common myna, estimates of density and abundance in 1996 included the villages, but the coastal scrubland and plantation forest were not surveyed (Baker et al., 1996). Common myna occurred at much greater densities within the three villages and in secondary forest in 1996 (20.4 and 12.9 per ha, respectively; Baker et al., 1996) than in our study (8.14 and 5.96 per ha). The estimated population of common myna on Mangaia has increased since 1996 (13,350 compared to 8,877 ; Baker et al., 1996), and this seems mainly related to the increased areas of secondary forest and village habitat reported here. Despite occurring at a lower density, we recorded more myna within the secondary forests in 2019 than in 1996 (7,570 compared to $5,121)$, and similarly within the villages $(2,290$ compared to $1,306)$. The decline in the density of the common myna in these two apparently preferred habitat types suggests that the population has declined since 1996.

Pineapple plantations were historically extensive throughout the island's interior, on the volcanic hills and in the surrounding fertile lowlands. Following the collapse of the industry in the 1980s, the pineapple plantations on the volcanic hills were replaced by plantation forest. In contrast, the land used for the cultivation of pineapples in the lowlands was left to regenerate into secondary forest. Furthermore, following the industry's collapse and the Cook Islands' financial crisis in 1996, the human population of Mangaia decreased from c. 1,500 people to $<500$ (G. Vaiimene, pers. comm., 2018). With a reduced population, the rate of deforestation probably slowed, although there are no empirical data to confirm this. It seems likely that the increase in tanga'eo reported here is linked to the increased availability of favourable habitat, as well as a reduction in habitat fragmentation and loss. Similarly, any past decline in tanga'eo would likely 
have been the result of habitat loss brought about by the widespread cultivation of pineapples.

We observed aggressive interactions between common myna and tanga' eo throughout our fieldwork, with tanga'eo more frequently the aggressor in such interactions. There is no evidence, however, to indicate that a decline in common myna is linked to an increase in the tanga'eo. Grarock et al. (2013) reported that the density of common myna declined with increasing tree density in Australia. Moreover, the rate of egg success (the proportion of eggs laid that hatched) for common myna in Australia dropped from $>90 \%$ in sites with a low density of trees to $56 \%$ in sites with high tree density (Grarock et al., 2013). The regeneration of secondary forest following the decline in pineapple cultivation could have affected the island's population of common myna negatively, although no data are available to confirm this.

Our findings suggest that the common myna population on Mangaia is not adversely affecting the tanga'eo population, despite the population size being approximately three times that of the tanga'eo. The 7-8 fold increase in the tanga'eo population since 1996 further suggests that intensive management of this species is not required. The tanga'eo is currently categorized as Vulnerable on the IUCN Red List because there are $<1$, ooo mature individuals (criterion D1), and it is confined to fewer than five locations (D2; BirdLife International, 2016). With an estimated total population of several thousand birds, the D1 criterion should be dropped in future assessments.

The species remains restricted to a single location, and this has been the basis for the $\mathrm{D}_{2}$ criterion in the past. The spectre of introduced alien species and diseases remains. Avian malaria, for example, has had a devastating effect on endemic species in Hawaii since its introduction in the early 2oth Century, with numerous species having been driven to extinction or having suffered reductions in their ranges (van Riper et al., 1986). However, although avian malaria has already spread to both French Polynesia (Beadell et al., 2006) and the Cook Islands (Ishtiaq et al., 2006) there is no evidence that the tanga'eo has been adversely affected. Rattus rattus and R. exulans have been introduced to Mangaia but do not appear to be exerting significant pressure upon the tanga'eo. Cyclones do not appear to pose a serious threat to this species, as the raised makatea encircling the island protects the primary and secondary forests where tanga'eo are most commonly found.

The $\mathrm{D}_{2}$ criterion is warranted only in circumstances where there exists a plausible future threat that could drive the species to become either Critically Endangered or extinct within a short period of time, in either one or two generations or 3-5 years, depending on which is longer (IUCN Standards \& Petitions Committee, 2019). Although habitat fragmentation remains a concern, it is unlikely that the degree of habitat loss necessary to propel the species to become Critically Endangered would occur within this time frame. The IUCN distributional criteria, such as the D2 criterion, have been criticized as inadequate for species endemic to small islands, and for unnecessarily increasing the number of species categorized as threatened (Martín, 2009). None of these threats are likely to drive the species to become Critically Endangered or extinct within the specified window required for the $\mathrm{D}_{2}$ criterion. We therefore recommend that the $\mathrm{D}_{2}$ criterion for the tanga'eo is reevaluated.

We recommend that distance sampling surveys of the tanga'eo are undertaken at least every 5 years, to track population size and allow managers to anticipate any need for intervention in the event of declines. Future analyses should include the method of detection (seen or heard) as a covariate, as this has been found to improve the fit of models for a number of other bird species (van Heezik \& Seddon, 2012).

Acknowledgements We thank the Cook Islands Government and the Mangaia Island Council for permission to carry out this research; the people of Mangaia, and the Te Ipukarea Society, for their support; and two anonymous reviewers for their comments. This research received no specific grant from any funding agency, or commercial or not-for-profit sectors.

Author contributions Study design: TT, PJS, YvH; fieldwork: TT; data analysis, writing: TT, PJS, YvH, GM.

\section{Conflicts of interest None.}

Ethical standards This research abided by the Oryx guidelines on ethical standards.

\section{References}

Andersen, M.J., McCullough, J.M., Mauck, W.M., Smith, B.T. \& Moyle, R.G. (2018) A phylogeny of kingfishers reveals an Indomalayan origin and elevated rates of diversification on oceanic islands. Journal of Biogeography, 45, 269-281.

Andersen, M.J., Shult, H.T., Cibois, A., Thibault, J.C., Filardi, C.E. \& Moyle, R.G. (2015) Rapid diversification and secondary sympatry in Australo-Pacific kingfishers (Aves: Alcedinidae: Todiramphus). Royal Society Open Science, 2, 140375.

Baker, C., Bottomley, C., Kelly, L., Payne, L. \& Whittle, M (1996) Mangaia '96: Final Report of the Oxford University Expedition to the Cook Islands to Study the Mangaia Kingfisher (Tanga'eo). 21 June-21 August 1996. Oxford University, Oxford, UK.

Beadell, J.S., Ishtiaq, F., Covas, R., Melo, M., Warren, B.H., Atkinson, C.T. et al. (2006) Global phylogeographic limits of Hawaii's avian malaria. Proceedings of the Royal Society B: Biological Sciences, 273, 2935-2944.

Birdife International (2016) Todiramphus ruficollaris. In The IUCN Red List of Threatened Species 2016: e.T22683465A92987289. dx.doi.org/10.2305/IUCN.UK.2016-3.RLTS.T22683465A92987289.en [accessed 26 June 2019].

Bland, L.M., Collen, B., Orme, C.D.L. \& Bielby, J. (2015) Predicting the conservation status of data-deficient species. Conservation Biology, 29, 250-259.

Brooks, T.M., Mittermeier, R.A., Mittermeier, C.G., Da Fonseca, G.A.B., Rylands, A.B., Konstant, W.R. et al. (2002) 
Habitat loss and extinction in the hotspots of biodiversity. Conservation Biology, 16, 909-923.

Buckland, S.T., Rexstad, E.A., Marques, T.A. \& Oedekoven, C.S. (2015) Distance Sampling: Methods and Applications-Methods in Statistical Ecology. Springer International Publishing, Basel, Switzerland.

Fleming, E. \& Blowes, A. (2003) Export Performance in South Pacific Countries with Inadequate Endowments of Natural Resources: Cook Islands, Kiribati, Niue and Tuvalu, 1960 to 1999. Working Paper Series in Agricultural and Resource Economics No. 2003-4. Graduate School of Agricultural and Resource Economics, University of New England, Armidale, Australia. ageconsearch. umn.edu/record/12948 [accessed 5 May 2020].

Fry, C.H., Fry, K. \& Harris, A. (1992) Kingfishers, Bee-Eaters \& Rollers: A Handbook. Princeton University Press, Princeton, USA.

Garcia-Del-Rey, E. (2009) The status of the Fuerteventura Stonechat Saxicola dacotiae: a new evaluation using distance sampling and GIS. Bird Conservation International, 19, 165-173.

Grarock, K., Lindenmayer, D.B., Wood, J.T., Tidemann, C.R. (2013) Does human-induced habitat modification influence the impact of introduced species? A case study on cavity-nesting by the introduced common myna (Acridotheres tristis) and two Australian native parrots. Environmental Management, 52, 958-970.

Ishtiaq, F., Beadell, J.S., Baker, A.J., Rahmani, A.R., Jhala, Y.V. \& FleischeR, R.C. (2006) Prevalence and evolutionary relationships of haematozoan parasites in native versus introduced populations of common myna Acridotheres tristis. Proceedings of the Royal Society B: Biological Sciences, 273, 587-594.

IUCN (2014) Field Trip Analysis of the 39th Steering Committee CEM in the Cook Islands: Impact of Forest Plantations on Water Resources and Erosion on the Island of Mangaia. iucn.org/backup_iucn/ cmsdata.iucn.org/downloads/report_mangaia_and_swot_final.pdf [accessed 5 May 2020].

IUCN Standards and Petitions Committee (2019) Guidelines for Using the IUCN Red List Categories and Criteria. Version 14. iucnredlist.org/documents/RedListGuidelines.pdf [24 March 2020].
Kesler, D.C., Ghestemme, T., Portier, E. \& Gouni, A. (2010) Cooperative breeding of the society kingfisher (Todiramphus veneratus). The Wilson Journal of Ornithology, 122, 46-50.

Martín, J.L. (2009) Are the IUCN standard home-range thresholds for species a good indicator to prioritise conservation urgency in small islands? A case study in the Canary Islands (Spain). Journal for Nature Conservation, 17, 87-98.

McCormack, G., Karika, I. \& Marsters, J. (2008) Tanga'eo Reproductive Monitoring Survey. Unpublished report. Cook Islands Natural Heritage Trust, Rarotonga, Cook Islands.

Merlin, M.D. (1991) Woody vegetation on the raised coral limestone of Mangaia, Southern Cook Islands. Pacific Science, 45, 131-151.

Myers, N., Mittermeler, R.A., Mittermeler, C.G., Da Fonseca, G.A.B. \& KeNT, J. (200o) Biodiversity hotspots for conservation priorities. Nature, 403, 853-858.

Parkes, J. (2006) Feasibility Plan to Eradicate Common Mynas (Acridotheres tristis) from Mangaia Island, Cook Islands. Landcare Research, Lincoln, New Zealand.

Pratt, H.D., Bruner, P.L. \& Berrett, D.G. (1987) A Field Guide to the Birds of Hawaii and the Tropical Pacific. Princeton University Press, Princeton, USA.

Rosenstock, S.S., Anderson, D.R., Giesen, K.M. \& Carter, M.F. (2012) Landbird counting techniques: current practices and an alternative. The Auk, 119, 46-53.

Rowe, S. \& EMpson, R. (1996a) Distribution and abundance of the tanga'eo or Mangaia kingfisher (Halcyon tuta ruficollaris). Notornis, 43, 35-42.

Sibley, C.G. \& Monroe, B.L. (1990) Distribution and Taxonomy of Birds of the World. Yale University Press, New Haven, USA.

van HeeziK, Y. \& Seddon, P.J. (2012) Accounting for detectability when estimating avian abundance in an urban area. New Zealand Journal of Ecology, 36, 391-397.

van Riper, C.I., van Riper, S.G., Goff, M.L. \& Laird, M. (1986) The epizootiology and ecological significance of malaria in Hawaiian land birds. Ecological Monographs, 56, 327-344. 